\title{
Enuresis Nocturna in children with asthma: prevalence and associated risk factors
}

\author{
Emin Ozkaya ${ }^{*}$, Seren Calıs Aydın², Mebrure Yazıcı ${ }^{1}$ and Rusen Dundaröz ${ }^{3}$
}

\begin{abstract}
Background: Enuresis Nocturna (EN) is a common disorders in childhood. Although many different underlying pathophysiological mechanisms have been proposed to explain EN, its etiology is multifactorial. Some reports demonstrate that there is an association between EN and allergic diseases.

To study (1) the prevalence of EN in children with asthma, (2) to determine the possible risk factors for EN in asthmatic children.

Methods: Five hundreds and six children aged 6-14 years-old diagnosed with asthma and 380 age-matched non-asthmatic controls were enrolled into this cross-sectional case-control study. We studied an allergy panel that included skin prick tests with (8 inhalant allergens), total IgE, and blood eosinophil count for both groups. Semi-structured interviews were conducted with the parents of children presenting EN. Factors associated with EN in children with asthma were analyzed using a logistic regression model.
\end{abstract}

Results: The prevalence of EN was significantly higher in children with asthma as compared to the controls: 132 $(26 \%), 43(11.5 \%)$ respectively ( $p=0.001)$. Emergency visits frequency, and family history of enuresis were higher in the asthmatic children with EN than in asthmatic children without EN. According to the logistic regression analysis, positive pollen sensitization ( $p=0.027, \mathrm{OR}=1.94)$, allergic rhinitis $(p=0.032, \mathrm{OR}=2.36)$, and high eosinophil count $(p=0.004, \mathrm{OR}=1.40)$ were independent risk factors for $\mathrm{EN}$ in children with asthma.

Conclusion: This study showed that the prevalence of EN in children with asthma was higher than in same age controls. Sensitization to pollens, allergic rhinitis and high blood eosinophil count associate to the EN in children with asthma.

Keywords: Asthma, Enuresis, Children, Risk factors, Autonomic dysfunction, Pollen allergy, Eosinophilia

\section{Background}

Asthma is the most common chronic childhood disease [1]. The cause of asthma is not yet completely understood, and there is no consensus about its etiology. Various factors have been implicated in the pathogenesis of childhood asthma [2], such as combined contribution of genetic predisposition environmental insults. A great deal of interest has recently been raised concerning the relationship between psychosocial factors and asthma morbidity [3-5].

Enuresis Nocturna (EN), common in childhood. Several theories have been proposed to explain the its pathogenesis, such as developmental delay, increased

\footnotetext{
* Correspondence: eozkaya@bezmialem.edu.tr; minozkaya@yahoo.com ${ }^{1}$ Department of Pediatrics, Division of Pediatric Allergy and Immunology, Bezmialem Vakif University Medical Faculty, Adnan Menderes Bulvari Vatan Caddesi, 34093 Fatih/Istanbul, Turkey

Full list of author information is available at the end of the article
}

urine output secondary to decrease in nocturnal antidiuretic hormone, detrusor hyperactivity, psycho-behavioral problems, sleep disorders [6-9]. Although many different underlying pathophysiological mechanisms have been proposed to explain EN, its etiology is multifactorial.

Some reports demonstrate an association between EN and allergic diseases [10, 11]. Avoiding food and inhaled allergens resulted in alleviation of the symptoms of asthma and EN [12]. Also some studies showed that total immunoglobulin E (IgE) level was higher than normal in $60 \%$ of the asthmatic children with EN, and that levels of eosinophilic cationic protein (ECP) are significantly higher than in controls $[10,13]$. It has also been showed that there is general or local bladder hypersensitivity in asthmatic children that associated with increased parasympathetic tone in both of diseases $[14,15]$. 
The objective of this study was to evaluate the prevalence of EN in children with asthma and to determine risk factors in cases presenting both diseases occur concomitantly.

\section{Methods}

\section{Participants}

We conducted a cross-sectional case -control study, 650 children diagnosed with stable mild-to-moderate atopic asthma from the authors' Bezmialem Vakif University Hospital Pediatric Allergy-Pulmonology outpatient clinic were enrolled consecutively between April 2011 and June 2013. The diagnosis and severity of asthma were defined according to Global Initiative for Asthma (GINA) [16] guidelines. Children were defined as asthmatic according to the following criteria:

a) recurrent episodes of at least one symptoms of asthma, including cough, wheezing, breathlessness, and chest tightness;

b) an improvement of at least $12 \%$ in baseline forced expiratory volume in $1 \mathrm{~s}$ (FEV1) after bronchodilator use.

A study questionnaire requesting demographic data and family history of atopy was obtained to each patient. Children with asthma which showed also allergic rhinitis symptoms or were prescribed rhinitis treatment previously or intermittently were included. We did not use polysomnography for diagnosis obstructive sleep apnea syndrome (OSAS), that may associated with EN in asthmatic children who have got allergic rhinitis symptoms due to ethical and financial problems. Informed consent was given by the family of the patients. Asthmatic children presenting lower urinary track system (LUTS) symptoms, structural urologic disease or urinary tract infections after an examination by Pediatric Nephrologists were excluded from the study. After exclusions the total number of the asthmatic children participating was 506.

The control group consisted of age matched 380 children (6-14 years), chosen from those who were periodically attending pediatric welfare clinics of the same hospital for regular checkups. Control patients were evaluated with regard to chronic and/or severe infections, autoimmune disorders, familial history of atopy, eosinophil counts and total IgE level. Children were included in the control group if they had no personal familial history of atopy, no signs of atopic disorder, and if they were negative for skin prick test.

\section{Blood samples}

Venous blood samples were taken from each patient Whole blood analysis was done and total serum IgE was measured. Serum samples for in vitro total IgE were obtained from children after $8 \mathrm{~h}$ of fasting, were than centrifuged for $10 \mathrm{~min}$ at $1200 \mathrm{rpm}$ and stored at $-20{ }^{\circ} \mathrm{C}$. Total serum IgE (IU/mL) was measured on an Immulite 2000 automated analyzer (DPC) using the chemiluminescent enzyme immunoassay method. Eosinophil counts were determined from venous blood samples using a Coulter Counter for leukocyte measurements (Beckman Coulter, Inc.).

\section{Skin prick tests}

Skin prick tests for major allergens (grass mixture, tree mixture, cereal weeds, mould mixture, cat, dog, cockroach, and house dust mites (HDM) - Dermatophagoides pteronyssinus, Dermatophagides farinea) were performed on the forearm of each patient (Allergopharma ${ }^{\circ}$, Germany). Histamine dihydrochloride $(10 \mathrm{mg} / \mathrm{ml})$ and saline were used as positive and negative controls, respectively. The test was considered positive if the average diameter of the weal was at least $3 \mathrm{~mm}$ bigger than the negative control.

\section{Enuresis Nocturna (EN) survey}

Enuresis was defined as bed-wetting during sleep in children $\geq$ five years of age, according to the International Children's Continence Society (ICCS) [17, 18]. EN can be isolated (monosymptomatic EN) or associated with daytime lower urinary tract (LUT) symptoms (Nonmonosymptomatic EN) and is subdivided into primary and secondary forms. We did not obtained detailed urological anamnesis that may be related to hyperactive bladder (non-monosymtomatic enuresis). For this reason, we only focused in this study prevalence of primary monosymptomatic EN in children with asthma rather than nonmonosymptomatic EN or secondary EN.

A semi-structured interview was designed by the authors. During the interview, which was held in the out-patient clinic, One member of the study team (SC) directly asked the questions about EN to the patients and/or caregivers. Patients were asked if they ever wet the bed at night more than once a week for at least three months after the age of five [17]. Paternal schooling, family income, daily life problems (school attainment, occupational or academic failure), family problems (conflicts and/or quarrels with family members), disease-related variables (frequency of hospitalization for asthma attacks in the previous year) and some demographic characteristics were also investigated. All children with a history of EN were consulted by the pediatric nephrology department of the same hospital for the further etiological evaluation. After a detailed urologic evaluation, 144 children diagnosed with structural, or infectious problems or having daytime were excluded from the study. 


\section{Statistical analysis}

Data were analyzed by using the SPSS version 16.5 (SPSS Inc., Chicago, IL, USA). Descriptive statistics (including mean and median for continuous variables, and frequencies for ordinal and nominal variables) were used to describe the data. $X^{2}$ test was used for the comparison of normally distributed categorical variables. Normally distributed parametric variables were compared between groups by using Student's $t$ test. A bivariate analysis was initially studied in order to examine differences between patients with or without EN using Pearson's $\chi^{2}$ test. Following bivariate analysis, logistic regression analysis was performed to estimate the prevalence of EN according to each potential confounder. Data were expressed as odds ratio (OR) and $95 \%$ confidence interval (CI). The $p$ value $<0.05$ was considered to be statistically significant.

\section{Results}

Table 1. summarizes the some clinical and demographic variables in study and control groups. Age and sex were similar between the groups. The prevalence of EN was $26 \%(n=132)$ in patients with asthma, while it was $11.5 \%(n=43)$ in control group $(p=0.001)$. A family history of enuresis was more prevalant in children with asthma plus EN than in those presenting isolated asthma $(p=0.034$, Table 2$)$.

Positive skin test ratios among the asthmatic children with and without EN was $67 \%$ and $40 \%$, respectively. Sensitization against all tested allergens was higher among the asthmatic children with EN than those without $(p<0.001$, Table 2$)$. Specifically for grass mixture, tree mixture and cereal mixture sensitization ratio in asthmatic children with EN was significantly higher than for those without EN $(p<0.001)$. Sensitization to other common aeroallergens (HDM, mold, cat, dog, and cockroach) was not significantly different between asthmatic children with and those without EN ( $p>0.05$, Table 2).

Among asthmatic children with enuresis, education level of the father and family history of atopy was statistically higher than in controls $(p<0,05$, Table 2$)$. The

Table 1 Some clinical and demographic characteristics of asthmatic children and controls

\begin{tabular}{llll}
\hline & $\begin{array}{l}\text { Patients } \\
N=506\end{array}$ & $\begin{array}{l}\text { Controls } \\
N=380\end{array}$ & $p$ value \\
\hline Age (mean) yrs, & $8.40 \pm 2.60$ & $8.8 \pm 1.90$ & 0.69 \\
Sex (male/n,\%) & $290(57 \%)$ & $198(52 \%)$ & 0.75 \\
EN $(n, \%)$ & $132(26 \%)$ & $43(11.5 \%)$ & 0.001 \\
Eosinophils/mm3 (mean \pm SD) & $386102 \pm 33)$ & $168(56 \pm 27)$ & 0.025 \\
Family history of Atopy $(n, \%)$ & $204(40 \%)$ & $35(17 \%)$ & 0.005 \\
\hline
\end{tabular}

$E N$, enuresis nocturna

Values are given as mean \pm standard deviation frequency of emergency visits during the last year was higher in children with asthma plus EN when compared with those without $(p=0.035)$. There was no significant difference between enuretic and non-enuretic asthmatic children in terms of total $\operatorname{IgE}(p=0.058, \mathrm{p}>0.05)$, but eosinophils count in asthmatic children with enuresis was statistically higher than in those without $(\mathrm{p}<0.05$, Table 2).

After adjusting for age and gender a logistic regression analysis was performed. As shown in Table 3, positive sensitization to pollens in skin prick test $[\mathrm{OR}=1.94$, $95 \% \mathrm{CI}, 1.47-4.48 ; p=0.027]$ high eosinophils count $[\mathrm{OR}=1.40,95 \% \mathrm{CI}, 1.63-3.27 ; p=0.004]$, and additional allergic rhinitis diagnosis $[\mathrm{OR}=2.36,95 \% \mathrm{CI}$, $1.86-4.94 ; \mathrm{p}=0.032]$ were independent risk factors for EN in children with asthma.

\section{Discussion}

Worldwide prevalence of EN ranges between 5 and $10 \%$ at ten years of age $[19,20]$. The reported prevalence of EN in healthy Turkey primary school-aged children ranges between 9 and $16 \%$ [21, 22]. Our cross-sectional data show an overall prevalence of EN of $26 \%$ in asthmatic children. This rate is statistically higher than EN incidence in healthy controls and our country average. Recent and past literature on the prevalence of EN in children with allergic diseases is very limited $[10,13]$. Also there is no published study primarily focused on prevalence of EN- associated risk factors in asthmatic children. This is the first paper to investigate the prevalence of EN in children with asthma.

Following allergic diseases, enuresis is the second most common chronic disorder in childhood [18], and leads to considerable psycho-behavioral problems and stress in affected children and their caregivers [23]. Its pathogenetic factors are nocturnal polyuria, detrusor over-activity and reduced arousability. Psychological and psychiatric aspects, genetics and obstipation play an additional role in the etiology [24]. Most of the studies of enuretic children do not show any relationship between anatomical defects and NE $[25,26]$. Therefore, it is though that EN may have a functional basis. Current evidence suggests that EN has multifactorial etiology which may underlie the different pathophysiologic mechanisms [18].

It has been suggested that some urinary disorders may be associated with allergy [13, 27]. EN was found to be associated with a reported history of asthma and allergic sensitization to common allergens [27]. Respiratory problems may determine or worsen enuresis. Jesus et al, reported in their cohort study a high incidence (54.3\%) of respiratory/ENT problems (asthma and adenoid hypertrophy) in children with complicated bladder dysfunction [28]. A metaanalysis with 3550 children with sleeping breath disorders showed that one-third had 
Table 2 Study variables in children with asthma according to the presence Nocturnal Enuresis

\begin{tabular}{|c|c|c|c|}
\hline & $\begin{array}{l}\text { Asthmatic children with NE } \\
N=132\end{array}$ & $\begin{array}{l}\text { Asthmatic children without NE } \\
N=374\end{array}$ & $p$ value \\
\hline Age (mean) yrs, & $7.3 \pm 2.1$ & $5.7 \pm 1.5$ & 0.038 \\
\hline Sex (male/n,\%) & $75(57 \%)$ & 198(52 \%) & 0.750 \\
\hline Family history of enuresis & $55(41 \%)$ & $101(26 \%)$ & 0.034 \\
\hline Serum IgE levels (IU/mL) & $86.7 \pm 25$ & $70.6 \pm 81$ & 0.583 \\
\hline Eosinophil/mm³ (mean \pm SD) & $386(102 \pm 33)$ & $168(56 \pm 27)$ & 0.025 \\
\hline Family history of Atopy (n,\%) & 204(40) & $35(17)$ & 0.034 \\
\hline Emergency visit (No, mean \pm SD) & $4.2(1.2)$ & $2.8(0.7)$ & 0.032 \\
\hline Positive allergic sensitization ( $n, \%)$ & $89(67)$ & $150(40)$ & 0.016 \\
\hline Pollen sensitization ( $n, \%)$ & $53(40)$ & $62(16)$ & 0.024 \\
\hline
\end{tabular}

$N E$, nocturnal enuresis

Values are given as mean \pm standard deviation

enuresis and that adenotonsilectomy provided relief of the urinary symptoms in half of the patients [29]. In contrast to these studies, Siegel et al [30], reported that there was no relationship between allergic disease and $\mathrm{EN}$ in school-age children.

The reasons that relate allergic disease and EN are uncertain. Both diseases show similarities, such as familial background, multifactorial and genetic base. One of the pathophysiologic mechanisms in the etiopathogenesis of $\mathrm{EN}$ is increased detrusor muscle activity due to excessive autonomic activation during sleep in children associated with autonomic nervous system dysregulation [31]. Researchers suggested that the parasympathetic nervous system hyperactivity may be a cause of vesical hyperactivity in enuretic children. Similarly, Emin et al [15], found a significant relationship between parasympathetic nervous system hyperactivity and disease severity in children with asthma. Our study results also related a higher prevalence of EN in children with uncontrolled asthma (as suggested by frequent emergency visits), as compared to well controlled asthmatic patients. Bed-wetting in EN and cough in asthma are both night-time symptom [32]. Brockmann et al., reported that excessive autonomic activation during sleep in children is a risk factor for EN [33]. Therefore, some autonomic nervous system dysregulation mechanism may partly explain both nocturnal cough in asthma and EN. We did not obtaine a detailed

Table 3 Multivariate logistic regression analysis of sensitization pattern, total IgE, eosinophil count, and additional allergic rhinitis in asthmatic children with $N E(N=132)$

\begin{tabular}{llll}
\hline & OR & $95 \% \mathrm{Cl}$ & $p^{*}$ \\
\hline Positive sensitization to pollens & $1.94^{*}$ & {$[1.47-4.48]$} \\
Eosinophil count & $1.40^{*}$ & {$[1.63-3.27]$} \\
Plus Allergic rhinitis & $2.36^{*}$ & {$[1.86-4.94]$} & \\
\hline
\end{tabular}

$N E$, nocturnal enuresis

${ }^{*} p<0.05$ urological anamnesis that might have detected to hyperactive bladder symptoms (non-monosymtomatic enuresis) in our asthmatic cohort, and cannot claim directly the possibility of autonomic imbalance in asthmatic children with EN.

Kaplan et al [34] reported that there were no differences in allergen sensitization to major food allergen between enuretic children and age-matched controls. In contrast to this study, Mungan et al [10] reported that there may be a relationship between EN and some food allergens. We did not research food allergens in our cohort due to restricted study budget.

It has been suggested that the bladder may be as sensitive as other end-organs like nose, lung, and skin for allergy [27]. After the inhaled allergens reaches the allergen-specific antibodies on mast cells or basophiles, mediators such as histamine, prostaglandins and other cytokines are released and promote smooth muscle contraction and mucus secretion. Smooth muscle contraction is well-known effect of all kind of inhalant allergens in the allergic reaction [35]. It was reported that allergens may decrease functional bladder capacity, cause bladder inflammation and smooth muscle contraction [11]. Zaleski et al, reported that EN is associated significantly with hay fever, urticaria and drug allergy [13]. Also, some studies showed that there is increased incidence of nocturnal detrusor contraction in $\mathrm{EN}[36,37]$. Our study provides evidence for an increased prevalence for EN in children with asthma with any pollen allergy. This independent associations remained when adjusting for other risk factors including age, gender, family history of atopy, and total IgE level suggesting that concurrent pollen sensitization is an independent risk factor for increased EN prevalence in children with asthma.

Nasal obstruction is one of the most prominent symptom in allergic rhinitis [38]. Aydil et al reported that obstructive upper airway problems are significant risk factors for EN in children [39]. Some studies report on 
the association between allergic rhinitis (AR) and sleepdisordered breathing (SDB) in children [40]. A systematic rewiev showed enuresis in $1 / 3$ of SDB children, in a cohort of 3350 cases [29]. In our study, allergic rhinitis in children with asthma was associated with increased risk for EN in asthmatic children. Obstructive upper airway problems and systemic allergic inflammation in children with both allergic rhinitis than asthma may be associated risks of EN in children. We could not obtaine further laboratory tests like polysomnography for diagnosis obstructive sleep apnea syndrome (OSAS) that may associated with EN in asthmatic children who have got allergic rhinitis symptoms due to ethical and financial problems. This is as a limitation of the our study.

Eosinophilic cystitis (EC), is a rare inflammatory disorder of the bladder of uncertain etiology Despite many case reports in both the adult and pediatric population, its etiology remains unclear. It is thought to be incited by an IgE mediated attraction of eosinophils to the bladder wall with subsequent mast cell degranulation. A history of previous systemic allergic conditions is frequently elicited from patients with EC. Presenting symptoms of EC are most frequently irritative in nature and mimic those of urinary tract infection: enuresis, dysuria, frequency, urgency, and hematuria [41]. Spark et al., reported that 27 (50\%) of the 54 patients with EC demonstrated either a significant eosinophilia or eosinophiluria [42]. In our study, a high eosinophils count was an as independent risk factors for EN in children with asthma. We did not perform further laboratory tests (eosinophiluria, cystoscopy, biopsy) for diagnosis of EC in our study population and cannot affirm that EN in children with asthma is associated with EC.

\section{Conclusion}

Asthma and enuresis frequently co-exist and enuresis is more frequent in asthmatic children than in controls. Asthmatic children with EN display increased blood eosinophil counts, pollen sensitization and allergic rhinitis when compared to children without enuresis. Pediatricians should be aware of the association between asthma and EN so that effective treatment can be offered to families.

\section{Acknowledgment}

Not applicable.

\section{Authors' contributions}

$\mathrm{EO}$, designed and analyzed data, wrote the manuscript and acted as corresponding author. SCA, MY, collected the data. RD, helped to evaluate, edit the manuscript and performed critical revision. All authors read and approved the final manuscript.

\section{Competing interest}

The authors have no financial or personal relationships with other people or organisation that could pose a conflict of interest in connection with the present work.

\section{Ethics approval and consent to participate}

The study is approved by the local ethics committee of Bezmialem Vakif University and follows the Declaration of Helsinki Good Clinical Practice Guidelines. Informed consent was given by the family of patients and controls.

\section{Author details}

'Department of Pediatrics, Division of Pediatric Allergy and Immunology, Bezmialem Vakif University Medical Faculty, Adnan Menderes Bulvari Vatan Caddesi, 34093 Fatih/Istanbul, Turkey. ${ }^{2}$ Department of Pediatrics, Giresun University Medical Faculty, Giresun, Turkey. ${ }^{3}$ Department of Pediatrics, Bezmialem Vakif University Medical Faculty, Adnan Menderes Bulvari Vatan Caddesi, 34093 Fatih/Istanbul, Turkey.

Received: 20 November 2015 Accepted: 30 May 2016

Published online: 10 June 2016

\section{References}

1. Asher I, Pearce N. Global burden of asthma among children. Int J Tuberc Lung Dis. 2014;18:1269-78.

2. Bierbaum S, Heinzmann A. The genetics of bronchial asthma in children. Respir Med. 2007:101:1369-75.

3. Wright RJ. Psychological stress: a social pollutant that may enhance environmental risk. Am J Respir Crit Care Med. 2011;1184:752-4.

4. Weil CM, Wade SL, Bauman L, Lynn H, Mitchell H, Lavigne J. The relationship between psychosocial factors and asthma morbidity in innercity children with asthma. Pediatrics. 1999;104:1274-80.

5. Chen E, Fisher EB, Bacharier LB, Strunk RC. Socioeconomic status, stress, and immune markers in adolescents with asthma. Psychosom Med. 2003:65:984-92.

6. Wolfe-Christensen C, Fedele DA, Grant D, Veenstra AL, Kovacevic LG, Elder $J S$, et al. Factor analysis of the pediatric symptom checklist in a population of children with voiding dysfunction and/or nocturnal enuresis. J Clin Psychol Med Settings. 2014;21:72-80.

7. Abou-Khadra MK, Amin OR, Ahmed D. Association between sleep and behavioural problems among children with enuresis. J Paediatr Child Health. 2013:49:160-6.

8. Alexopoulos El, Malakasioti G, Varlami V, Miligkos M, Gourgoulianis K, Kaditis AG. Nocturnal enuresis is associated with moderate-to-severe obstructive sleep apnea in children with snoring. Pediatr Res. 2014;76:555-9.

9. Gür E, Turhan P, Can G, Akkus S, Sever L, Güzelöz S, et al. Enuresis: prevalence, risk factors and urinary pathology among school children in Istanbul, Turkey. Pediatr Int. 2004;46:58-63.

10. Mungan NA, Seckiner I, Yesilli C, Akduman B, Tekin IO. Nocturnal enuresis and allergy. Scand J Urol Nephrol. 2005;39:237-41.

11. Yamada T, Murayama T, Mita H, Akiyama K. Bladder hypersensitivity of interstitial cystitis complicated by allergic diseases. Urology. 2001:57(6 Suppl 1):125

12. Bray GW. Enuresis of Allergic Origin. Arch Dis Child. 1931;6:251-3.

13. Zaleski A, Shokeir MK, Gerrad JW. Enuresis: famlial incidence and relationship to allergic disorders. Can Med Assoc Journal. 1972;106:30-1.

14. Unalacak M, Aydin M1, Ermis B, Ozeren A, Sogut A, Demirel F, et al. Assessment of cardiac autonomic regulation in children with monosymptomatic nocturnal enuresis by analysis of heart rate variability. Tohoku J Exp Med. 2004;204:63-9.

15. Emin O, Esra G, Aysegül D, Ufuk E, Ayhan S, Rusen DM. Autonomic nervous system dysfunction and their relationship with disease severity in children with atopic asthma. Respir Physiol Neurobiol. 2012;183:206-10.

16. Global Initiative for Asthma (GINA). Global strategy for asthma management and prevention. Updated. 2008. Available on line at www.ginasthma.org/ guidelineitem.asp. Accessed 25 Mar 2015.

17. Nevéus T, von Gontard A, Hoebeke P, Hjälmås K, Bauer S, Bower W, et al. The standardization of terminology of lower urinary tract function in children and adolescents: Report from the Standardization Committee of the International Children's Continence Society. J Urol. 2006;176:314-24.

18. DiBianco JM, Morley C, Al-Omar O. Nocturnal enuresis: A topic review and institution experience. Avicenna J Med. 2014;4:77-86.

19. Bakhtiar K, Pournia Y, Ebrahimzadeh F, Farhadi A, Shafizadeh F, Hosseinabadi $R$. Prevalence of nocturnal enuresis and its associated factors in primary school and preschool children of khorramabad in 2013. Int J Pediatr. 2014;2014:120686 
20. Ozkan S, Durukan E, Iseri E, Gürocak S, Maral I, Ali BM. Prevalence and risk factors of monosymptomatic nocturnal enuresis in Turkish children. Indian J Urol. 2010;26:200-5.

21. Doganer YC, Aydogan U, Ongel K, Sari O, Koc B, Saglam K. The Prevalence and Sociodemographic Risk Factors of Enuresis Nocturna among Elementary School-age Children. J Family Med Prim Care. 2015;4:39-44.

22. Carman KB, Ceran O, Kaya C, Nuhoglu C, Karaman MI. Nocturnal enuresis in Turkey: prevalence and accompanying factors in different socioeconomic environments. Urol Int. 2008;80:362-6.

23. Longstaffe S, Moffatt ME, Whalen JC. Behavioral and self-concept changes after six months of enuresis treatment: a randomized, controlled trial. Pediatrics. 2000;105(4 Pt 2):935-40.

24. Riccabona M. Evaluation and management of enuresis. An update. Urologe A. 2010;49:861-9. German.

25. Azhir A, Nasseri F, Fazel A, Adibi A, Frajzadegan Z, Divband AH. Etiology and pathology of enuresis among primary school children in Isfahan, Iran. Saudi Med J. 2007:28:1706-10.

26. Cayan S, Doruk E, Bozlu M, Akbay E, Apaydin D, Ulusoy E, et al. Is routine urinary tract investigation necessary for children with monosymptomatic primary nocturnal enuresis? Urology. 2001;58:598-602.

27. Morfín-Maciel BM. Correlation between renal-uretero-bladder diseases and allergies. Rev Alerg Mex. 2002;49:60-5. Spanish.

28. Jesus LE, Tomé A, Cobe D, Camelier P. Psychosocial and respiratory disease related to severe bladder dysfunction and non-monosymptomatic enuresis. J Pediatr Urol. 2015;5131(15):451-9.

29. Jeyakumar A, Rahman SI SI, Ambrecht ES, Mitchell R. The association between sleep-disordered breathing and enuresis in children. Laryngoscope. 2012;122(8):1873-7.

30. Siegel S, Rawitt L, Sokoloff B, Siegel B. Relationship of allergy, enuresis, and urinary infection in children 4 to 7 years of age. Pediatrics. 1976;57:526-8.

31. Yakinci C, Müngen B, Durmaz Y, Balbay D, Karabiber H. Autonomic nervous system functions in children with nocturnal enuresis. Brain Dev. 1997;19:485-7

32. Strunk RC, Sternberg AL, Bacharier LB, Szefler SJ. Nocturnal awakening caused by asthma in children with mild-to-moderate asthma in the childhood asthma management program. J Allergy Clin Immunol. 2002;110:395-403.

33. Brockmann PE, Urschitz MS, Noehren A, Sokollik C, Schlaud M, Poets CF. Risk factors and consequences of excessive autonomic activation during sleep in children. Sleep Breath. 2011;15:409-16.

34. Kaplan GW, Wallace WW, Orgel HA, Miller JR. Serum immunoglobulin E and incidence of allergy in group of enuretic children. Urology. 1977;10:428-30.

35. Jiang H, Rao K, Halayko AJ, Liu X, Stephens NL. Ragweed sensitizationinduced increase of myosin light chain kinase content in canine airway smooth muscle. Am J Respir Cell Mol Biol. 1992;7:567-73.

36. Nørgaard JP, Djurhuus JC. The pathophysiology of enuresis in children and young adults. Clin Pediatr (Phila). 1993 Jul;Spec No:5-9.

37. Nørgaard JP, Djurhuus JC, Watanabe H, Stenberg A, Lettgen B. Experience and current status of research into the pathophysiology of nocturnal enuresis. Br J Urol. 1997:79:825-35.

38. de Oliveira GM M, Rizzo JA, Camargos PA, Sarinho ES. Are measurements of peak nasal flow useful for evaluating nasal obstruction in patients with allergic rhinitis? Rhinology. 2015;53:160-6.

39. Aydil U, Işeri E, Kizil Y, Bodur S, Ceylan A, Uslu S. Obstructive upper airway problems and primary enuresis nocturna relationship in pediatric patients: reciprocal study. J Otolaryngol Head Neck Surg. 2008;37:235-9.

40. Lin SY, Melvin TA, Boss EF, Ishman SL. The association between allergic rhinitis and sleep-disordered breathing in children: a systematic review. Int Forum Allergy Rhinol. 2013;3(6):504-9.

41. Abilov A, Ozcan R, Polat E, Dervişoğlu S, Emir H. Rare cause of dysuria: eosinophilic cystitis. J Pediatr Urol. 2013:9:6-8.

42. Sparks S, Kaplan A, DeCambre M, Kaplan G, Holmes N. Eosinophilic cystitis in the pediatric population: a case series and review of the literature. J Pediatr Urol. 2013:9:738-44.

\section{Submit your next manuscript to BioMed Central and we will help you at every step:}

- We accept pre-submission inquiries

- Our selector tool helps you to find the most relevant journal

- We provide round the clock customer support

- Convenient online submission

- Thorough peer review

- Inclusion in PubMed and all major indexing services

- Maximum visibility for your research

Submit your manuscript at www.biomedcentral.com/submit
) Biomed Central 